\title{
Baseline JAK phosphorylation profile of peripheral blood leukocytes, studied by whole blood phosphospecific flow cytometry, is associated with 1-year treatment response in early rheumatoid arthritis
}

Krista Kuuliala ${ }^{1 *}$, Antti Kuuliala', Riitta Koivuniemi ${ }^{2}$, Hannu Kautiainen ${ }^{3,4,5}$, Heikki Repo ${ }^{1}$ and Marjatta Leirisalo-Repo ${ }^{2}$

\begin{abstract}
Background: We found recently that baseline signal transducer and activator of transcription 3 phosphorylation in peripheral blood $C D 4^{+} T$ cells of patients with early rheumatoid arthritis (RA) is associated with treatment response to synthetic disease-modifying antirheumatic drugs (DMARDs). This prompted us to study the baseline phosphorylation profiles of Janus kinases (JAKs) in blood leukocytes with respect to treatment response in early RA.

Methods: Thirty-five DMARD-naïve patients with early RA provided blood samples for whole blood flow cytometric determination of phosphorylation of JAKs in $\mathrm{CD}^{+}$and $\mathrm{CD} 8^{+} \mathrm{T}$ cells, CD19 $\mathrm{B}$ cells, and $\mathrm{CD} 14^{+}$monocytes. Treatment response was determined after 1 year of treatment with synthetic DMARDs, with remission defined as absence of tender and swollen joints and normal erythrocyte sedimentation rate. Exact logistic regression was used to investigate the association of baseline variables with treatment response. Ninety-five percent Cls of means were estimated by bias-corrected bootstrapping.

Results: High JAK3 phosphorylation in $\mathrm{CD}^{+}$and $\mathrm{CD} 8^{+} \mathrm{T}$ cells, CD19+ $\mathrm{B}$ cells, and CD14 $4^{+}$monocytes and low JAK2 phosphorylation in $\mathrm{CD}_{1} 4^{+}$monocytes were significantly associated with remission following treatment with synthetic DMARDs.
\end{abstract}

Conclusions: Baseline JAK phosphorylation profile in peripheral blood leukocytes may provide a means to predict treatment response achieved by synthetic DMARDs among patients with early RA.

Keywords: Rheumatoid arthritis, Disease-modifying antirheumatic drug, Janus kinases, Phosphorylation, Blood, Leukocyte, Biomarker

\footnotetext{
* Correspondence: krista.kuuliala@helsinki.fi

'Bacteriology and Immunology, Helsinki University Hospital and University of

Helsinki, Helsinki, Finland

Full list of author information is available at the end of the article
} 


\section{Background}

Rheumatoid arthritis (RA) is a chronic autoimmune disease characterized by inflammatory synovitis; articular destruction; extra-articular manifestations; and, when not responding to treatment satisfactorily, progressive disability and increased mortality. The disease is heterogeneous, and its pathogenetic mechanisms are not clear, but they are known to involve both genetic and environmental factors as well as innate and adaptive immunity [1]. Synthetic disease-modifying antirheumatic drugs (sDMARDs) are the first treatment option in untreated RA, used either as monotherapy or in various combinations [2-4]. Recently, highly selective immunological agents have been developed for the treatment of RA, including biological disease-modifying antirheumatic drugs (DMARDs), especially blockers of inflammatory cytokines and immune cell surface receptors [5], and agents inhibiting intracellular signal transduction pathway members. As to the latter, Janus kinases (JAKs) are tempting targets because they are required for classical immune cytokine receptor signal transduction and consequently are involved in the pathophysiology of several inflammatory and immune disorders $[6,7]$. Despite the multiple drug options for treatment of RA, the lack of reliable predictive biomarkers poses a challenge to finding the most effective and suitable treatment for each individual rapidly, preferably within 3-4 months from the onset of symptoms [8].

A few years ago, we started to study the phosphorylation of the signal transducer and activator of transcription (STAT) transcription factors as biomarkers of disease activity and treatment response in RA [9]. We found that baseline phosphorylation of STAT3 in whole blood leukocytes is associated with the treatment response achieved by use of sDMARDs [10]. In the present study, we made progress in studying the JAK-STAT pathway and aimed at elucidating if JAK phosphorylation levels are able to distinguish DMARD-naïve patients with RA who will respond well to sDMARDs from those who will require still other treatment options. Using a phosphospecific whole blood flow cytometric method, we measured the baseline phosphorylation levels of all known JAKs (i.e., JAK1, JAK2, JAK3, and tyrosine kinase 2 [Tyk2]) in whole blood T cells, B cells, and monocytes of patients with early untreated RA.

\section{Methods}

\section{Subjects}

The study included 35 patients diagnosed with early RA at the Division of Rheumatology, Helsinki University Central Hospital, Helsinki, Finland, between April 2012 and April 2013. The patients fulfilled the American College of Rheumatology/European League Against Rheumatism 2010 classification criteria [11]. At study entry, the patients had received no DMARDs or oral glucocorticoids. Twenty-one healthy volunteers (62\% women; mean age 47 years [SD 13 years]) with no infectious symptoms or history of autoimmune disease and derived from hospital and laboratory staff served as reference subjects. All subjects were white Finnish persons residing in the Helsinki metropolitan area. The study protocol was approved by the ethical review board of the Joint Authority for the Hospital District of Helsinki and Uusimaa, and written informed consent was obtained from each patient.

\section{Clinical evaluation}

A comprehensive clinical and laboratory evaluation was undertaken at entry concomitant to blood sampling. Joints were evaluated for swelling and pain (66 and 68 joints, respectively). Patient global assessment of disease activity was recorded on a $100-\mathrm{mm}$ visual analogue scale. Laboratory measurements, including white blood cell count, erythrocyte sedimentation rate (ESR), and plasma C-reactive protein (CRP) level, were logged. The 28-joint Disease Activity Score (DAS28) was calculated [12]. After a mean 12-month follow-up, the patients were reexamined. Patients with no tender or swollen joints (68 and 66 joints, respectively) and normal ESR were considered to be in remission.

\section{Blood samples}

At study entry, an 8-ml blood sample was taken by venipuncture from the antecubital vein into a Falcon polypropylene tube (BD Biosciences, Bedford, MA, USA) supplemented with $800 \mu \mathrm{l}$ of pyrogen-free acid citrate dextrose solution $\mathrm{A}$ (ACD-A; Baxter Healthcare Ltd, Thetford, UK). Cells were prepared for flow cytometry within $3 \mathrm{~h}$ of blood sampling.

\section{Antibodies}

The following antibodies were purchased from BD Biosciences (San Jose, CA, USA): fluorescein isothiocyanate (FITC)-conjugated anti-CD14 (MфP9), anti-CD4 (SK3), and anti-CD19 (SJ25C1); phycoerythrin (PE)-conjugated anti-CD3 (SP34-2); peridinin chlorophyll protein complex (PerCP)-conjugated anti-CD3 (SK7); Alexa Fluor 647-conjugated anti-CD8 (RPA-T8) mouse anti-human monoclonal antibodies; and PE-conjugated anti-rabbit secondary antibody. Anti-phosphorylated (anti-p)-JAK1 (PhosphoDetect Tyr1022/1023) rabbit anti-human antibody was purchased from EMD Millipore (Darmstadt, Germany). The following antibodies were purchased from Santa Cruz Biotechnology (Dallas, TX, USA): antipJAK2 (Tyr1007/Tyr1008), anti-pJAK3 (Tyr980), antipTyk2 (Tyr1054) rabbit anti-human antibodies, and PerCP-conjugated anti-rabbit secondary antibody. The 
amounts of the antibodies were optimized, and their compatibility was assured in preliminary examinations.

\section{Preparing leukocytes for flow cytometry}

Blood leukocytes were prepared for flow cytometry using a protocol and buffers by BD Biosciences [13]. Aliquots $(50 \mu \mathrm{l})$ of blood were deposited into 12 polystyrene tubes (BD Biosciences). Four tubes were supplemented with anti-CD14-FITC, four with anti-CD4-FITC and antiCD8-Alexa Fluor 647, and four with anti-CD19-FITC for surface marker staining of monocytes, $\mathrm{CD} 4^{+} / \mathrm{CD} 8^{+} \mathrm{T}$ cells, and B cells, respectively. Following a 15-minute incubation at $37{ }^{\circ} \mathrm{C}$, leukocytes were fixed and erythrocytes lysed by adding 1× Lyse/Fix Buffer (BD Biosciences). After being pelleted, leukocytes were permeabilized and washed by incubating them twice in 1× Perm/Wash Buffer (BD Biosciences) at room temperature protected from light for 15 minutes. Cells were pelleted and resuspended in Perm/Wash Buffer. One tube each containing anti-CD14, anti-CD4 and anti-CD8, and anti-CD19 were supplemented with either anti-pJAK1, anti-pJAK2, anti-pJAK3, or anti-pTyk2. The tubes were incubated at room temperature protected from light for $1 \mathrm{~h}$, and then cells were pelleted and resuspended in Perm/Wash Buffer. Tubes containing the anti-pJAK1, anti-pJAK2, or anti-pTyk2 were supplemented with PE-conjugated secondary antibody, and tubes containing anti-pJAK3 were supplemented with PerCP-conjugated secondary antibody. The anti-CD4and anti-CD8-containing tubes, as well as the antiCD19-containing tubes, were also supplemented with the T-cell marker antibody anti-CD3-PerCP (for antipJAK1, anti-pJAK2, and anti-pTyk2 tubes) or anti-CD3PE (for anti-pJAK3 tubes). Following incubation at room temperature protected from light for 40 minutes, cells were washed in Perm/Wash Buffer and suspended in Stain Buffer (BD Biosciences). The samples were kept on ice for a maximum of $3 \mathrm{~h}$ until flow cytometric acquisition.

\section{Flow cytometry}

Flow cytometric data were acquired using a BD FACSCanto II flow cytometer and analyzed with BD FACSDiva software (BD Biosciences), as described previously [14]. $\mathrm{CD}^{+} \mathrm{CD}^{+}$and $\mathrm{CD}^{+}{ }^{+} \mathrm{CD} 8^{+} \mathrm{T}$ lymphocytes, $\mathrm{CD} 19^{+}$ $\mathrm{B}$ lymphocytes, and $\mathrm{CD} 14^{+}$monocytes were identified, and pJAK1-PE, pJAK2-PE, pJAK3-PerCP, and pTyk2-PE fluorescence intensities of the respective cell populations were determined as relative fluorescence units (RFU).

\section{Statistical analysis}

The data are presented as means with SDs and numbers of patients with percentages, and groups were compared using a permutation test or chi-square test. Exact logistic regression was used to investigate crude and adjusted relationships of the study entry variables to remission at 12 months. The $95 \%$ CIs of means were estimated by bias-corrected bootstrapping (5000 replications). pJAK1PE, pJAK2-PE, pTyk2-PE, and pJAK3-PerCP fluorescence intensities are presented as standardized fluorescence intensities (mean 0, SD 1) of RFU. Correlation coefficients were calculated by the Spearman method using Šidák-adjusted probabilities. The Stata 14.1 statistical software package (StataCorp, College Station, TX, USA) was used for the analyses.

\section{Results}

\section{Treatment and outcome}

The study included 35 DMARD-naïve patients with recent-onset RA (Table 1). After blood sampling, 33 patients started sDMARD therapy (methotrexate, sulfasalazine, hydroxychloroquine) according to the Finnish national care guidelines [4] (Table 1). In addition, 16 patients $(46 \%)$ started a course of low-dose ( $\leq 10 \mathrm{mg} /$ day) oral prednisone. Intra-articular glucocorticoid injections were also applied to treat swollen joints according to the Finnish national guidelines [4].

During follow-up (mean duration 12 months, SD 3.6 months), the drug treatment was modified when appropriate, targeting remission. After follow-up, 33 patients (91\%) were on sDMARDs, including 3 patients (9\%) on oral prednisone. Twenty patients (57\%) were in remission (no swollen or tender joints, and normal ESR). No patients were on biological DMARDs. The patients in remission started with a lower DAS28 score, lower number of tender joints, and lower patient global assessment at study entry (Table 1).

\section{Phosphorylation levels of JAKs}

Baseline phosphorylation of levels of JAKs were compared between the patients who subsequently were in remission after 12-month follow-up and the patients who were not (Fig. 1). JAK3 phosphorylation in $\mathrm{CD}^{+}$and $\mathrm{CD} 4^{+} \mathrm{T}$ cells and $\mathrm{CD} 19^{+} \mathrm{B}$ cells was found to be higher in the patients who achieved remission than in those who did not ( $p$ values of $0.015,0.024$, and 0.038 , respectively). No correlations were found between baseline JAK phosphorylation levels and plasma ESR or plasma CRP levels (data not shown).

In order to further elucidate the predictive value of JAK phosphorylation in each cell population, crude and adjusted exact logistic regression models of the baseline phosphorylation levels of JAK1, JAK2, JAK, and Tyk2 were constructed (Table 2). In the models adjusted for anti-cyclic citrullinated peptide, number of DMARDs started at entry, smoking, and white blood cell count, high phosphorylation level of JAK3 was associated with remission in all leukocyte types studied. In addition, low 
Table 1 Baseline characteristics of the patients categorized according to remission at 12-month follow-up

\begin{tabular}{|c|c|c|c|c|}
\hline \multirow[t]{2}{*}{ Variable } & \multirow[t]{2}{*}{ All patients $(n=35)$} & \multicolumn{2}{|c|}{ Remission at follow-up } & \multirow[t]{2}{*}{$p$ Value } \\
\hline & & $\mathrm{No}(n=15)$ & Yes $(n=20)$ & \\
\hline Age, years, mean (SD) & $55(14)$ & $57(15)$ & $53(14)$ & 0.43 \\
\hline Female sex, $n(\%)$ & $28(80 \%)$ & $15(75 \%)$ & $13(87 \%)$ & 0.39 \\
\hline Rheumatoid factor-positive, $n(\%)$ & $26(74 \%)$ & $10(67 \%)$ & $16(80 \%)$ & 0.37 \\
\hline Anti-citrullinated protein antibody-positive, $n(\%)$ & $27(77 \%)$ & $10(67 \%)$ & $17(85 \%)$ & 0.20 \\
\hline Smokers, $n(\%)$ & $8(23 \%)$ & $5(33 \%)$ & $3(15 \%)$ & 0.20 \\
\hline Duration of symptoms, months, mean (SD) & $6(7)$ & $6(10)$ & $6(4)$ & 0.89 \\
\hline Number of tender joints, 0-68, mean (SD) & $7(6)$ & $10(7)$ & $6(5)$ & 0.040 \\
\hline Number of swollen joints, 0-66, mean (SD) & $6(5)$ & $6(4)$ & $7(6)$ & 0.78 \\
\hline Erythrocyte sedimentation rate, mm/h, mean (SD) & $19(15)$ & $22(18)$ & $16(13)$ & 0.32 \\
\hline Plasma C-reactive protein, mg/L, mean (SD) & $7(7)$ & $6(3)$ & $8(9)$ & 0.41 \\
\hline White blood cell count, $\times 10^{9} / \mathrm{L}$, mean (SD) & $6.9(2.4)$ & $7.5(3.1)$ & $6.5(1.6)$ & 0.23 \\
\hline Patient global assessment, 0-100-mm VAS, mean (SD) & $40(25)$ & $54(24)$ & $31(21)$ & 0.0073 \\
\hline DAS28 score, mean (SD) & $3.63(1.14)$ & $4.08(1.19)$ & $3.29(1.01)$ & 0.040 \\
\hline Number of DMARDs started, mean (range) & $2.2(0-3)$ & $2.1(1-3)$ & $2.3(0-3)$ & 0.72 \\
\hline Single DMARD, $n$ & 4 & 2 & 2 & \\
\hline Combination of two DMARDs, $n$ & 13 & 9 & 4 & \\
\hline Combination of three DMARDs, $n$ & 16 & 4 & 12 & \\
\hline None, $n$ & 2 & 0 & 2 & \\
\hline
\end{tabular}

Abbreviations: VAS Visual analogue scale, DAS28 28-Joint Disease Activity Score, DMARD Disease-modifying antirheumatic drug

${ }^{a}$ Significance of difference between No and Yes groups calculated using permutation test or chi-square test

JAK2 phosphorylation level in $\mathrm{CD}_{1} 4^{+}$monocytes at baseline emerged to be associated with remission.

Tyk2 phosphorylation level was higher in patients than in healthy reference subjects in all leukocyte types studied (Table 3$)$ : $\mathrm{CD}^{+} \mathrm{T}$ cells $(p=0.0014), \mathrm{CD}^{+} \mathrm{T}$ cells $(p$ $=0.037), \mathrm{CD}_{19}{ }^{+} \mathrm{B}$ cells $(p=0.049)$, and CD14 ${ }^{+}$monocytes $(p<0.001)$. This indicated constitutive activation of Tyk2 in the patients' circulating leukocytes. Also, JAK2 phosphorylation of $\mathrm{CD} 14^{+}$monocytes was higher in patients than in healthy reference subjects $(p=0.011)$ (Table 3).

\section{Discussion}

The results of the present study show that high baseline JAK3 phosphorylation in all peripheral blood leukocyte subtypes studied (i.e., $\mathrm{CD}^{+}$and $\mathrm{CD}^{+} \mathrm{T}$ cells, B cells, and monocytes) is associated with remission achieved by sDMARDs among patients with early untreated RA. The JAK signaling profile of the patients who turned out as good sDMARD responders also included low JAK2 phosphorylation in $\mathrm{CD} 14^{+}$monocytes. Although there is evidence of JAK activation within inflamed joints observed in a few studies using animal models [15] or synovial cells from patients with RA [16-18], there are no prior studies, to the best of our knowledge, on the phosphorylation of JAKs in peripheral blood leukocytes of patients with RA. Consequently, the potential of the JAK phosphorylation profile in leukocytes as a predictor of treatment response in RA has not been studied before.

There are a number of possible explanations for the association we found between baseline JAK3 phosphorylation level and treatment response. First, the sDMARDs used can be effective in downregulating JAK3-involving inflammatory pathways, although the detailed mechanisms remain to be elucidated. In this context, it may be noteworthy that JAK3 cannot be replaced by other JAKs in transducing signals from the receptors of interleukin (IL)-2, IL-4, IL-7, IL-9, IL-15, and IL-21 ( $\gamma \mathrm{c}$ receptors) [7]. These cytokines are among those whose levels in peripheral blood are affected by DMARDs [19-22], which may represent a disease-modifying mechanism involving JAK3 signaling. Second, the anti-inflammatory or regulatory processes that are also triggered by JAK3 can possibly facilitate the amelioration of RA. It has been observed that JAK3 signaling limits T-helper cell type 17 differentiation in $\mathrm{CD}^{+} \mathrm{T}$ cells [23], maintains circulating quiescent $\mathrm{T}$ cells [24], and negatively regulates the production of inflammatory cytokines in innate immune cells $[25,26]$. In fact, in developing kinase inhibitor therapies for the treatment of RA, the challenge is to halt the pathogenic effects while preserving the homeostatic and advantageous effects of the kinases [27]. 

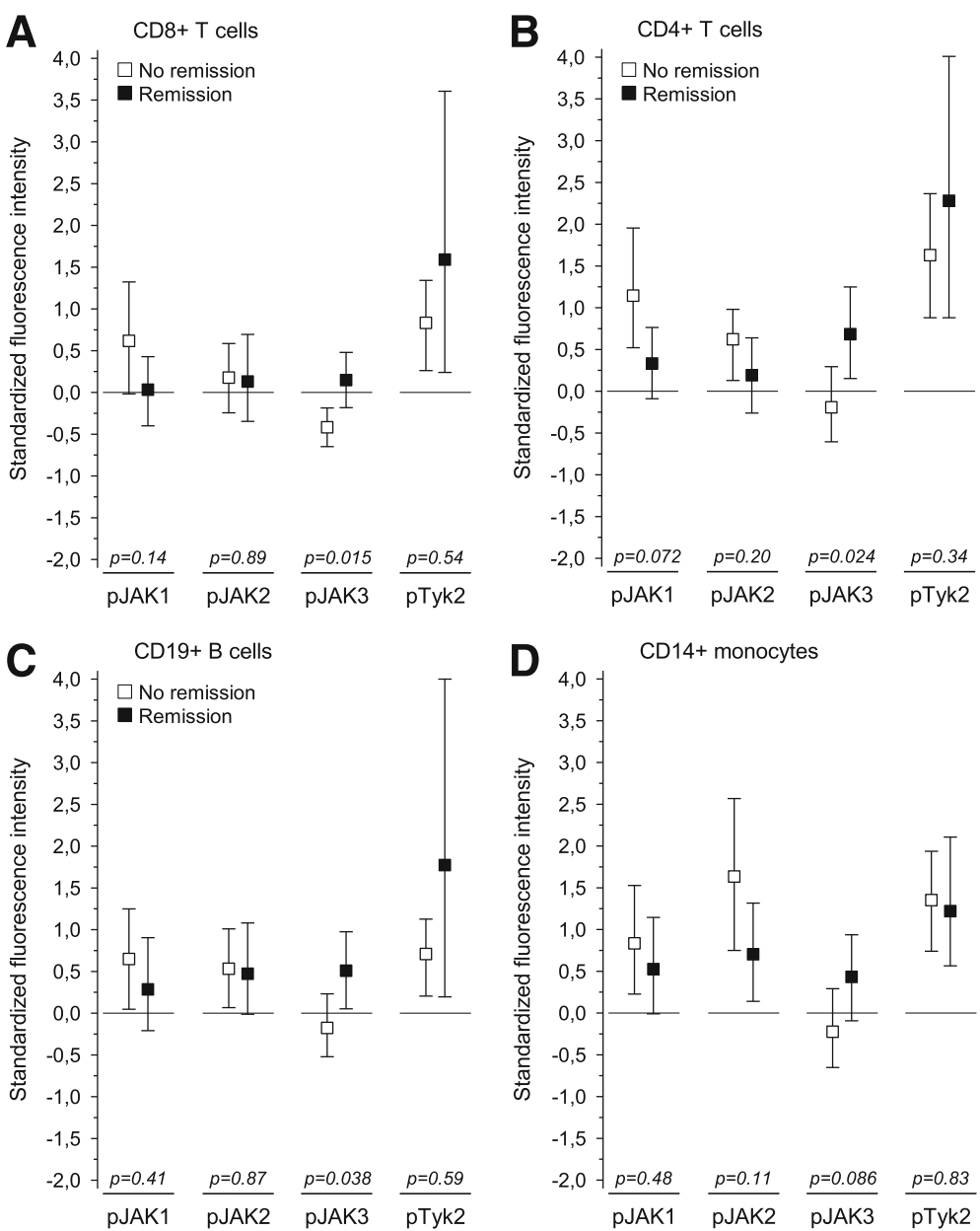

Fig. 1 Baseline Janus kinase phosphorylation (pJAK) profiles of peripheral blood a CD8+ T cells, b CD4+ T cells, c CD19+ B cells, and $\mathbf{d}$ CD14+ monocytes according to remission at 12-month follow-up. Squares indicate group means, and whiskers indicate group 95\% Cls. The fluorescence intensities are standardized to controls (mean 0 and SD 1). Horizontal lines show controls' means. Remission groups are compared using a permutation test

Table 2 ORs for remission after 1 year of follow-up

\begin{tabular}{|c|c|c|c|c|c|c|c|c|c|}
\hline \multirow[t]{2}{*}{ Model } & \multirow[t]{2}{*}{ Variable } & \multicolumn{2}{|l|}{$\mathrm{CD}^{+} \mathrm{T}$ cells } & \multicolumn{2}{|l|}{$\mathrm{CD}^{+} \mathrm{T}$ cells } & \multicolumn{2}{|l|}{$\mathrm{CD}_{19}{ }^{+} \mathrm{B}$ cells } & \multicolumn{2}{|c|}{ CD14 ${ }^{+}$monocytes } \\
\hline & & OR $(95 \% \mathrm{Cl})$ & $p$ Value & OR $(95 \% \mathrm{Cl})$ & $p$ Value & OR $(95 \% \mathrm{Cl})$ & $p$ Value & OR $(95 \% \mathrm{Cl})$ & $p$ Value \\
\hline \multirow[t]{4}{*}{ Unadjusted } & pJAK1 & $0.57(0.25-1.18)$ & 0.14 & $0.47(0.18-1.03)$ & 0.053 & $0.75(0.36-1.49)$ & 0.42 & $0.78(0.38-1.56)$ & 0.49 \\
\hline & pJAK2 & $0.96(0.48-1.89)$ & 0.90 & $0.63(0.30-1.26)$ & 0.20 & $0.95(0.48-1.88)$ & 0.88 & $0.55(0.25-1.10)$ & 0.092 \\
\hline & pJAK3 & $3.01(1.20-9.55)$ & 0.017 & $2.40(1.08-6.11)$ & 0.032 & $2.19(1.03-5.32)$ & 0.044 & $1.84(0.91-4.00)$ & 0.094 \\
\hline & pTyk2 & $1.34(0.64-3.24)$ & 0.49 & $1.23(0.61-2.84)$ & 0.61 & $1.46(0.65-3.78)$ & 0.44 & $0.92(0.46-1.82)$ & 0.80 \\
\hline \multirow[t]{4}{*}{ Adjusted $^{a}$} & pJAK1 & $0.42(0.13-1.14)$ & 0.083 & $0.46(0.16-1.09)$ & 0.077 & $0.68(0.30-1.49)$ & 0.32 & $0.84(0.36-1.94)$ & 0.70 \\
\hline & pJAK2 & $0.97(0.46-2.1)$ & 0.94 & $0.53(0.25-1.20)$ & 0.14 & $0.66(0.29-1.42)$ & 0.29 & $0.42(0.16-0.96)$ & 0.034 \\
\hline & pJAK3 & $3.87(1.33-16.65)$ & 0.009 & $2.73(1.16-7.90)$ & 0.017 & $2.87(1.11-8.87)$ & 0.029 & $2.22(1.01-5.31)$ & 0.045 \\
\hline & pTyk2 & $1.40(0.64-3.25)$ & 0.45 & $1.32(0.62-3.05)$ & 0.52 & $1.47(0.63-3.47)$ & 0.44 & $0.92(0.45-1.93)$ & 0.83 \\
\hline
\end{tabular}


Table 3 Baseline phosphorylatad Janus kinase fluorescence intensities in peripheral blood leukocytes of patients and healthy reference subjects

\begin{tabular}{|c|c|c|c|c|}
\hline Fluorescence & Cell type & Patients $(n=35)$ & Healthy control subjects $(n=17)$ & $p$ Value \\
\hline \multirow[t]{4}{*}{ pJAK1-PE } & $\mathrm{CD}^{+} \mathrm{T}$ & $385(92)$ & $335(75)$ & 0.054 \\
\hline & $\mathrm{CD}^{+} \mathrm{T}$ & $387(89)$ & $365(79)$ & 0.41 \\
\hline & $\mathrm{CD} 19^{+} \mathrm{B}$ & $549(151)$ & $497(121)$ & 0.23 \\
\hline & $\mathrm{CD}_{14}^{+} \mathrm{Mo}$ & $863(240)$ & 737 (193) & 0.06 \\
\hline \multirow[t]{4}{*}{ PJAK2-PE } & $\mathrm{CD}^{+} \mathrm{T}$ & $4443(1446)$ & $3885(1484)$ & 0.20 \\
\hline & $\mathrm{CD} 8^{+} \mathrm{T}$ & $4282(1792)$ & $4016(1761)$ & 0.62 \\
\hline & $\mathrm{CD} 19^{+} \mathrm{B}$ & 7675 (3026) & $6340(2680)$ & 0.12 \\
\hline & $\mathrm{CD}_{14}^{+} \mathrm{Mo}$ & $6571(2703)$ & $4727(1674)$ & 0.011 \\
\hline \multirow[t]{4}{*}{ pJAK3-PerCP } & $\mathrm{CD} 4^{+} \mathrm{T}$ & $823(197)$ & $773(163)$ & 0.37 \\
\hline & $\mathrm{CD}^{+} \mathrm{T}$ & $1350(283)$ & $1388(396)$ & 0.69 \\
\hline & $\mathrm{CD}_{19}{ }^{+} \mathrm{B}$ & $1040(214)$ & $994(213)$ & 0.47 \\
\hline & $\mathrm{CD}_{14}^{+} \mathrm{Mo}$ & $2035(442)$ & $1976(385)$ & 0.65 \\
\hline \multirow[t]{4}{*}{ pTyk2-PE } & $\mathrm{CD} 4^{+} \mathrm{T}$ & $380(144)$ & $297(41)$ & 0.001 \\
\hline & $\mathrm{CD} 8^{+} \mathrm{T}$ & 342 (128) & $287(43)$ & 0.037 \\
\hline & $\mathrm{CD}_{19}{ }^{+} \mathrm{B}$ & 361 (177) & $295(51)$ & 0.049 \\
\hline & $\mathrm{CD}_{14}^{+} \mathrm{Mo}$ & $1118(342)$ & 827 (228) & $<0.001$ \\
\hline
\end{tabular}

Abbreviations: $p J A K$ Phosphorylated Janus kinase, Mo Monocyte, PE Phycoerythrin, PerCP Peridinin chlorophyll protein complex, Tyk Tyrosine kinase

The fluorescence intensities are shown as means (SDs) in relative fluorescence units, with $p$ values calculated using a permutation test

The association between low JAK2 phosphorylation in monocytes and good treatment response may reflect the critical roles of JAK2 in innate immune responses. It has been demonstrated in monocytic cells that JAK2 inhibition blunts the production of both early and late inflammatory mediators [28], and that the prolonged effect of interferon- $\gamma$ on lipopolysaccharide-induced tumor necrosis factor production is apparently mediated by JAK2 [29]. It is noteworthy that the JAK inhibitor tofacitinib has high affinity for JAK3, but it also inhibits JAK1 and, to a lesser extent, JAK2, and also STAT1 and STAT3 [6]. Thus, the efficacy of tofacitinib in treating RA $[6,7,30]$ may actually be due to its effects on target molecules other than JAK3. It has also been reported on the basis of in vitro studies on rheumatoid synovial fibroblasts that JAK3-selective inhibition is insufficient to control the proinflammatory cascade, and inhibition of JAK1 and JAK2 may be needed instead [31].

It should be noted that because the patients' JAK3 phosphorylation levels overlapped with those of healthy reference subjects, they cannot serve as diagnostic markers for RA. The phenomenon in which levels of a marker distinguish patients with RA according to divergent outcomes while not distinguishing patients from healthy control subjects has recently been described for other potential markers, including microRNAs [32]. Hence, JAK3 phosphorylation may serve as a surrogate marker, and the possibility remains that markers that discriminate patients with RA from healthy individuals will be discovered along the same signaling pathway.
We also observed that, in contrast to the other JAKs, Tyk2 phosphorylation in lymphocytes and monocytes of patients with RA was significantly higher than in those of healthy reference subjects. Because this phosphorylation was not associated with measures of disease activity or treatment response, the context of the finding remains elusive. Tyk2, for its part, promotes interferon- $\gamma$ production [33] and can be activated by IL-13 [34]. Methotrexate treatment (which was an essential sDMARD in our study) reduces the levels of both of these cytokines in patients with RA [19]. So, it is possible that Tyk2 phosphorylation increases along with the inflammatory processes during the development of RA and decreases along with the amelioration achieved by sDMARDs, but its effects are not directly related to clinical manifestations of RA. Interestingly, genetic variants of Tyk2 have been reported to protect against RA, systemic lupus erythematosus, and possibly other autoimmune diseases, such as inflammatory bowel disease [35]. Accordingly, Tyk2 phosphorylation in patients with early RA (as a consequence of either genetic factors or pathogenetic processes) may be associated with increased risk for development of RA, though not directly correlating to disease activity.

The quite low number of subjects is a limitation of the present study. The strengths of the study include the advantages of the phosphospecific whole blood flow cytometric method we used. Blood samples were easily obtained, and only a small volume of blood (a couple of milliliters) was required. Also, ex vivo phosphorylation 
due to sample handling was minimized, and the procedure was quick (within hours) and has been evaluated as being applicable for rapid immune status determination before starting immunomodulatory therapy in inflammatory diseases [36]. If our results are confirmed in larger studies, it is possible that JAK3 phosphorylation, either alone or with other markers from, for example, the JAKSTAT pathway, is able to serve as treatment response marker in RA.

\section{Conclusions}

Baseline JAK phosphorylation profile in circulating leukocytes of patients with early untreated RA is associated with treatment response achieved with sDMARDs. High JAK3 phosphorylation level in both $\mathrm{CD}^{+}$and $\mathrm{CD}^{+} \mathrm{T}$ cells, in $\mathrm{CD} 19^{+} \mathrm{B}$ cells, and in $\mathrm{CD} 14^{+}$monocytes is a promising predictor of good treatment response to sDMARDs in RA.

\section{Abbreviations \\ CRP: C-reactive protein; DAS28: 28-joint Disease Activity Score; DMARD: Disease-modifying antirheumatic drug; ESR: Erythrocyte sedimentation rate; FITC: Fluorescein isothiocyanate; IL: Interleukin; JAK: Janus kinase; Mo: Monocyte; PE: Phycoerythrin; PerCP: Peridinin chlorophyll protein complex; RA: Rheumatoid arthritis; RFU: Relative fluorescence unit; sDMARD: Synthetic disease-modifying antirheumatic drug; STAT: Signal transducer and activator of transcription; Tyk: Tyrosine kinase; VAS: Visual analogue scale}

\section{Acknowledgements}

The authors thank Maija-Leena Peltoperä for excellent technical assistance.

\section{Funding}

The study was supported by Paulo Foundation and Finnish Cultural Foundation (to KK), and by Helsinki University Central Hospital Research Funds and Finska Läkaresällskapet (to MLR and HR).

\section{Availability of data and materials}

The dataset generated during the present study is available from the corresponding author on reasonable request.

\section{Authors' contributions}

$K K, A K, H R$, and MLR conceived of and designed the study, analyzed and interpreted the data, and drafted the manuscript. KK and AK carried out the laboratory work. RK and MLR recruited and examined the patients. HK carried out the statistical analysis. All authors helped to critically revise the manuscript for intellectual content. All authors read and approved the final manuscript.

\section{Competing interests}

The authors declare that they have no competing interests.

\section{Consent for publication}

Not applicable.

\section{Ethics approval and consent to participate}

The study protocol was approved by the ethical review board of the Joint Authority for the Hospital District of Helsinki and Uusimaa, and written informed consent was obtained from each patient.

\section{Publisher's Note}

Springer Nature remains neutral with regard to jurisdictional claims in published maps and institutional affiliations.

\section{Author details}

Bacteriology and Immunology, Helsinki University Hospital and University of Helsinki, Helsinki, Finland. ${ }^{2}$ Rheumatology, Helsinki University Hospital and University of Helsinki, Helsinki, Finland. ${ }^{3}$ Primary Health Care, Helsinki University Hospital and University of Helsinki, Helsinki, Finland. ${ }^{4}$ General Practice, Helsinki University Hospital and University of Helsinki, Helsinki, Finland. ${ }^{5}$ Unit of Primary Health Care, Kuopio University Hospital, Kuopio, Finland.

Received: 23 November 2016 Accepted: 10 March 2017

Published online: 11 April 2017

\section{References}

. Mclnnes IB, Schett $G$. The pathogenesis of rheumatoid arthritis. N Engl J Med. 2011;365:2205-19.

2. Smolen JS, Landewé R, Breedveld FC, Dougados M, Emery P, Gaujoux-Viala $C$, et al. EULAR recommendations for the management of rheumatoid arthritis with synthetic and biological disease-modifying antirheumatic drugs. Ann Rheum Dis. 2010;69:964-75.

3. Singh JA, Saag KG, Bridges Jr SL, Akl EA, Bannuru RR, Sullivan MC, et al. 2015 American College of Rheumatology Guideline for the Treatment of Rheumatoid Arthritis. Arthritis Care Res (Hoboken). 2016:68:1-25.

4. Working group appointed by the Finnish Medical Society Duodecim and the Finnish Society for Rheumatology. Rheumatoid arthritis [in Finnish]. In: Current Care Guidelines. The Finnish Medical Society Duodecim. 2015. http://www.kaypahoito.fi/web/kh/suositukset/suositus?id=hoi21010. Accessed 22 Aug 2016.

5. Tak P, Kalden JR. Advances in rheumatology: new targeted therapeutics. Arthritis Res Ther. 2011;13 Suppl 1:S5

6. Ghoreschi K, Laurence A, O'Shea J. Janus kinases in immune cell signaling. Immunol Rev. 2009;228:273-87.

7. Laurence A, Pesu M, Silvennoinen O, O'Shea J. JAK kinases in health and disease: an update. Open Rheumatol J. 2012;6:232-44.

8. van Nies JA, Tsonaka R, Gaujoux-Viala C, Fautrel B, van der Helm-van Mil AH. Evaluating relationships between symptom duration and persistence of rheumatoid arthritis: does a window of opportunity exist? Results on the Leiden early arthritis clinic and ESPOIR cohorts. Ann Rheum Dis. 2015;74: 806-12.

9. Kuuliala K, Kuuliala A, Aittomäki S, Oksanen S, Siitonen S, Kautiainen H, et al. STAT3 phosphorylation of circulating leukocytes correlates with disease activity in early untreated rheumatoid arthritis. Arthritis Rheum. 2011;63 Suppl 10:S1008

10. Kuuliala K, Kuuliala A, Koivuniemi R, Oksanen S, Hämäläinen M, Moilanen E, et al. Constitutive STAT3 phosphorylation in circulating CD4 ${ }^{+}$T lymphocytes associates with disease activity and treatment response in recent-onset rheumatoid arthritis. PLoS One. 2015;10:e0137385.

11. Aletaha D, Neogi T, Silman AJ, Funovits J, Felson DT, Bingham 3rd CO, et al. 2010 rheumatoid arthritis classification criteria: an American College of Rheumatology/European League Against Rheumatism collaborative initiative. Ann Rheum Dis. 2010;69:1580-8.

12. Prevoo ML, van 't Hof MA, Kuper HH, van Leeuwen MA, van de Putte LB, van Riel PL. Modified disease activity scores that include twenty-eight-joint counts: development and validation in a prospective longitudinal study of patients with rheumatoid arthritis. Arthritis Rheum. 1995:38:44-8.

13. BD Biosciences. Technical data sheet: BD Perm/Wash Buffer. http://www bdbiosciences.com/ds/pm/tds/554723.pdf. Accessed 22 Aug 2016.

14. Oiva J, Mustonen $H$, Kylänpää $M L$, Kyhälä L, Kuuliala K, Alanärä T, et al. Acute pancreatitis with organ dysfunction associates with abnormal blood lymphocyte signaling: controlled laboratory study. Crit Care. 2010;14:R207.

15. Shahrara S, Amin MA, Woods JM, Haines GK, Kock AE. Chemokine receptor expression and in vivo signaling pathways in the joints of rats with adjuvant-induced arthritis. Arthritis Rheum. 2003:48:3568-83.

16. Walker JG, Ahern MJ, Coleman M, Weedon H, Papangelis V, Beroukas D, et al. Changes in synovial tissue Jak-STAT expression in rheumatoid arthritis in response to successful DMARD treatment. Ann Rheum Dis. 2006;65:1558-64.

17. Carrión M, Juarranz Y, Martinez C, González-Àlvaro |, Pablos UL, GutiérrezCanas I, et al. IL-22/IL-22R1 axis and S100A8/A9 alarmins in human osteoarthritic and rheumatoid arthritis synovial fibroblasts. Rheumatology (Oxford). 2013;52:2177-86. 
18. Li CH, Xu LL, Zhao JX, Sun L, Yao ZQ, Deng XL, et al. CXCL16 upregulates RANKL expression in rheumatoid arthritis synovial fibroblasts through the JAK2/STAT3 and p38/MAPK signaling pathway. Inflamm Res. 2016:65:193-202.

19. Gerards AH, de Lathouder S, de Groot ER, Dijkmans BAC, Aarden LA. Inhibition of cytokine production by methotrexate: studies in healthy volunteers and patients with rheumatoid arthritis. Rheumatology. 2003;42: 1189-96.

20. van Roon JA, Jacobs K, Verstappen S, Bijlsma J, Lafeber F. Reduction of serum interleukin 7 levels upon methotrexate therapy in early rheumatoid arthritis correlates with disease suppression. Ann Rheum Dis. 2008;67:1054-5.

21. Ally MM, Hodkinson B, Meyer PW, Musenge E, Tintinger GR, Tikly M, et al. Circulating anti-citrullinated peptide antibodies, cytokines and genotype as biomarkers of response to disease-modifying antirheumatic drug therapy in early rheumatoid arthritis. BMC Musculoskelet Disord. 2015;16:130.

22. Kremer JM, Lawrence DA, Hamilton R, Mclnnes IB. Long-term study of the impact of methotrexate on serum cytokines and lymphocyte subsets in patients with active rheumatoid arthritis: correlation with pharmacokinetic measures. RMD Open. 2016;2:e000287.

23. Martín P, Gómez M, Lamana A, Cruz-Adalia A, Ramírez-Huesca M, Ursa MA, et al. CD69 association with Jak3/Stat5 proteins regulates Th17 cell differentiation. Mol Cell Biol. 2010;30:4877-89.

24. Sohn SJ, Forbush KA, Nguyen N, Witthuhn B, Nosaka T, Ihle JN, et al. Requirement for Jak3 in mature T cells: its role in regulation of T cell homeostasis. J Immunol. 1998:160:2130-8.

25. Wang H, Brown J, Gao S, Liang S, Jotwani R, Zhou H, et al. The role of JAK-3 in regulating TLR-mediated inflammatory cytokine production in innate immune cells. J Immunol. 2013;191:1164-74.

26. Kim HJ, Hart J, Knatz N, Hall MW, Wewers MD. Janus kinase 3 downregulates lipopolysaccharide-induced IL-1 $\beta$-converting enzyme activation by autocrine IL-10. J Immunol. 2004;172:4948-55.

27. Chakravarty SD, Poulikakos PI, Ivashkiv LB, Salmon JE, Kalliolas GD. Kinase inhibitors: a new tool for the treatment of rheumatoid arthritis. Clin Immunol. 2013;148:66-78.

28. Pena G, Cai B, Deitch EA, Ulloa L. JAK2 inhibition prevents innate immune responses and rescues animals from sepsis. J Mol Med. 2010:88:851-9.

29. Lee JY, Sullivan KE. Gamma interferon and lipopolysaccharide interact at the level of transcription to induce tumor necrosis factor alpha expression. Infect Immun. 2001;69:2847-52.

30. Schwartz DM, Bonelli M, Gadina M, O'Shea JJ. Type I/II cytokines, JAKs, and new strategies for treating autoimmune diseases. Nat Rev Rheumatol. 2016; 12:25-36.

31. Migita K, Izumi Y, Torigoshi T, Satomura K, Izumi M, Nishino Y, et al. Inhibition of Janus kinase/signal transducer and activator of transcription (JAK/STAT) signalling pathway in rheumatoid synovial fibroblasts using small molecule compounds. Clin Exp Immunol. 2013;174:356-63.

32. Filková M, Aradi B, Senolt L, Ospelt C, Vettori S, Mann H, et al. Association of circulating miR-223 and miR-16 with disease activity in patients with early rheumatoid arthritis. Ann Rheum Dis. 2014:73:1898-904.

33. Karaghiosoff M, Steinborn R, Kovarik P, Kriegshäuser G, Baccarini M, Donabauer B, et al. Central role for type I interferons and Tyk2 in lipopolysaccharide-induced endotoxin shock. Nat Immunol. 2003;4:471-7.

34. Roy B, Bhattacharjee A, XU B, Ford D, Maizel AL, Cathcart MK. IL-13 signal transduction in human monocytes: phosphorylation of receptor components, association with Jaks, and phosphorylation/activation of Stats. J Leukoc Biol. 2002;72:580-9.

35. Diogo D, Bastarache L, Liao KP, Graham RR, Fulton RS, Greenberg JD, et al. TYK2 protein-coding variants protect against rheumatoid arthritis and autoimmunity, with no evidence of major pleiotropic effects on nonautoimmune complex traits. PLoS One. 2015;10:e0122271.

36. Caldwell CC, Hotchkiss RS. The first step in utilizing immune-modulating therapies: immune status determination. Crit Care. 2011;15:108.

\section{Submit your next manuscript to BioMed Central and we will help you at every step:}

- We accept pre-submission inquiries

- Our selector tool helps you to find the most relevant journal

- We provide round the clock customer support

- Convenient online submission

- Thorough peer review

- Inclusion in PubMed and all major indexing services

- Maximum visibility for your research

Submit your manuscript at www.biomedcentral.com/submit
Biomed Central 